\title{
Study of the Effect of Waste Glass Fibers Incorporation on the Collapsible Soil Stability Behavior
}

\section{Nassima bakir ${ }^{1}$, Khelifa Abbeche ${ }^{2}$, Gérard Panczer ${ }^{3}$, and Larbi Belagraa ${ }^{1,4}$}

${ }^{1}$ Department of Civil Engineering, Faculty of Technology, University of M'sila, M'sila 28000, Algeria

${ }^{2}$ Department of Civil Engineering, Faculty of Technology, University of Batna2, Batna 5000, Algeria

${ }^{3}$ Institute Light and Matter, UMR5306 Université Lyon 1-CNRS, Université de Lyon 69622 Villeurbanne cedex, France

${ }^{4}$ Laboratory of Materials and Electronic Systems, Faculty of Science and Technology, University Bachir Ibrahimi Bordj Bou Arreridj, 34 030, Algeria

\section{Abstract}

Soil collapse remains a major issue affecting structural foundations, particularly in arid and semi-arid zones where humidification is a key factor contributing to the collapse.

Corresponding Author:

Nassima bakir

nassima.bakir@univ-msila.dz

Received: 20 March 2020

Accepted: 30 April 2020

Published: 13 April 2020

Publishing services provided by Knowledge E

(c) Nassima bakir et al. This article is distributed under the terms of the Creative Commons

Attribution License, which

permits unrestricted use and redistribution provided that the original author and source are credited.

Selection and Peer-review under the responsibility of the RICON19 - REMINE International Conference Conference Committee.

\section{G OPEN ACCESS}

Much research has been devoted to identifying treatment methods which enhance the stability and load bearing capacity of this type of soil. This paper investigates the potential advantages of the addition of milled glass fibers $\left(F_{g}\right)$. Soil samples were prepared at different compaction energies and various water contents, then treated with different percentages of milled glass fiber, before being submitted to the simple consolidation odometer test. The results obtained in this study showed that soil samples treated with an optimal dosage of $6 \%$ of milled glass fibers compacted at 60 blows and humidified at $6 \%$ of moisture content. This represents an improvement in the stability of the soil, reducing the collapse potential $\left(C_{p}\right)$ from $11.95 \%$ to $1.62 \%$. This treatment method produces soil which can be classified as a moderate risk foundation soil according to the Jennings and Knight evaluation metrics (1975).

Keywords: collapsible soils, arid zones, fiberglass, odometer test.

\section{Introduction}

One of the most important geotechnical problems in the world, especially in arid and semi-arid regions, is that of collapsible soils, as they can be a real danger for the foundations stability and consequently for the constructions built on it if they are not substituted or treated. Studies claim that the loess covers about $17 \%$ of the United States, about 17 \% of Europe, 15 \% of Russia and Siberia, and large areas of China [1]. A study by Nouaouria et al., showed that the properties of loess in southern Algeria are similar to those existing in other regions such as the soil of lowa (USA) and Libya, this kind of soil can be classified as a silty loess [2]. 
The collapsible soils, due to their specific particle size, their low dry density and their reduced water content, are unsaturated metastable soils with a loose and open structure. Such soils can support heavy loads in the dry state, however, their humidification, even without additional loading, causes the disintegration of the connections giving a denser structure followed by an important settlement.

The treatment of collapsible soils in arid and semi-arid regions is a major issue in both economic and security aspects. Indeed, several researchers have focused on the study of the treatment of this type of soil with the aim of exploiting it without any danger.

A method using lime was proposed by Abbeche et al. [3]. Another one using cement was studied with the double odometer [4], This study showed that for a minimum compaction, a cement content of $4 \%$ and a water content of $6 \%$, the soil is not collapsible. But Mohamed and El Gamal have concluded that the treatment of collapsible soil by sulfur cement, increases its compressive strength by about three times than the ones stabilized by Portland cement [5].

Fattah et al. affirm by their study that the treatment of undisturbed collapsible gypsum samples with acrylate liquid, with different properties and with various gypsum contents, can reduce the collapse potential by more than $50-60 \%$ [6-8].

In this paper, a new soil treatment is proposed, which will be carried out with different percentages of a milled glass-fiber. The soil will be subject to different compaction levels and different water contents in order to find the needed rate to reduce the soil subsidence, and thus to improve security level for the structures built on this type of soil.

\section{Experimental Study}

Tests were conducted on soil samples reconstituted in the laboratory with the composition of $80 \%$ of sand ( $<<2 \mathrm{~mm}$ ), and $20 \%$ of kaolin as fine particles (grains size $<80 \mu \mathrm{m})$. The stream sand is from Oued Maitar at Boussaâda (Algeria) and the clay is a kaolin of Elmilia region located in Mila (eastern Algeria). The treatment is carried out with a milled glass-fiber $(\mathrm{Fg})$ often used for its mechanical, thermal and chemical resistance (E-glass, product specification $1320 \mathrm{~K}$, fiber length: $180 \mu \mathrm{m})$. The geotechnical characteristics of the laboratory reconstituted soil are summarized in Table 1 and its particle size distribution curve is shown in Figure 1. 
TABLE 1: Geotechnical characteristics of reconstituted soil

Liquid limit, $\mathrm{W}_{L \%}$
Plastic limit $\mathrm{W}_{p \%}$
Specific density, $\mathrm{G}_{S}$
Coefficient of uniformity, $\mathrm{C}_{u}$
Coefficient of curvature, $\mathrm{C}_{c}$
Maximum dry density $\mathrm{V}_{o p t}\left(\mathrm{~g} / \mathrm{cm}^{3}\right)$
Optimal water content $\mathrm{W}_{o p t \%}$

\begin{tabular}{|c|}
\hline 18.53 \\
13.13 \\
2.63 \\
\hline 9.44 \\
2.64 \\
1.91 \\
10
\end{tabular}

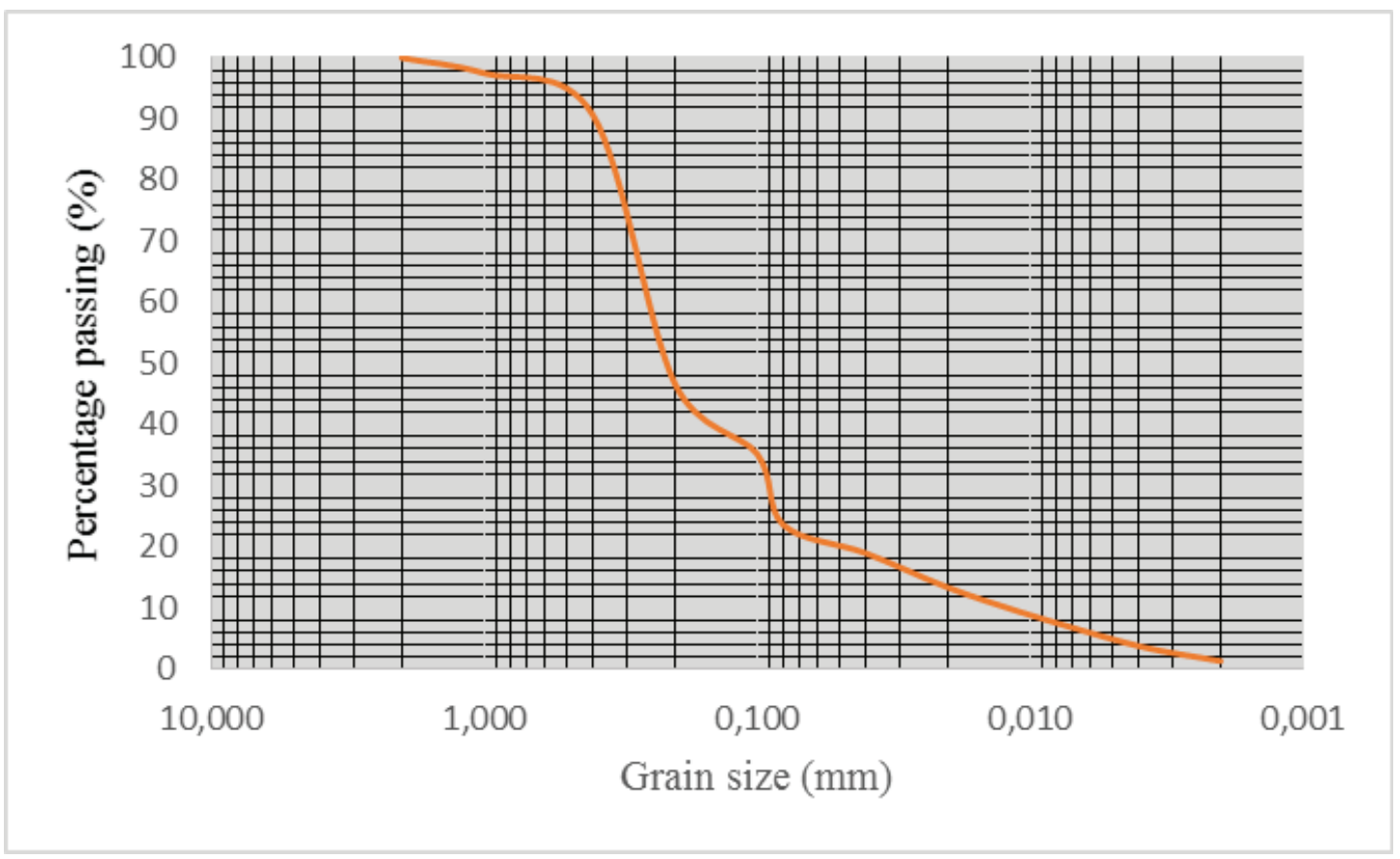

Figure 1: Grain size distribution curve of the reconstituted soil

\section{Experimental Program}

The study consists in consolidation in the oedometer [9], of samples according to the procedure of Jennings and Knight [10]. The samples were prepared at different moisture contents and compaction energy. Then, the same test will be carried on samples of soil treated with different percentages of milled glass-fiber. Content in glass-fiber is varied in order to determine the rate beyond of which the collapse $C_{p}$ becomes without any danger for the structure "no damages" according to the classification of Jennings and Knight [10], Table 2. The reserved parameters are:

- Initial water contents: 2, 4 and $6 \%$;

- Energy of compaction 20, 40 and 60 blows; 
- Contents in glass-fiber: 0, 3, 4, 5 and $6 \%$.

TABLE 2: Collapse Potential Values (Jennings and Knight 1975)

$\mathbf{C}_{p}(\%)$
$0-1 \%$
$1-5 \%$
$5-10 \%$
$10-20 \%$
$>20 \%$

\begin{tabular}{|c|}
\hline Severity odisorders \\
Without risk \\
\hline Moderate trouble \\
Trouble \\
\hline Severe trouble S \\
\hline Very severe trouble
\end{tabular}

\section{Test Procedure}

The first stage of sample preparation is to mix the two components (sand and kaolin) to obtain a well homogenized soil. The soil is then compacted at a given water content in a standard oedometric mold in one layer due to the small height of the ring $(20 \mathrm{~mm})$. The equipment used for the compaction procedure, which was made at the laboratory, is composed of a disk having a diameter slightly smaller than that of the ring, which is fixed to a stem of guidance and a disk shaped weight. The weight of $121 \mathrm{~g}$, sliding along the stem and falling from $15 \mathrm{~cm}$ height, comes to strike the disk, compacting thereby the material in the oedometer ring. The total compaction energy $\mathrm{E}_{c}$ at stake for a soil specimen, being the work of the mass $M(\mathrm{~kg})$ at a height $h(\mathrm{~m})$, is expressed by the equation:

$$
\mathrm{E}_{c}=\mathrm{Mghn} \text { (joules) }
$$

Where $\mathrm{n}$ is the number of strokes of the mass $\mathrm{M}$, and $\mathrm{g}$ the acceleration gravity.

The oedometer tests are made according to Jennings and Knight's procedure which consists in the application of loads: 25, 50, 100 until $200 \mathrm{kPa}$, then the sample is flooded with water and a new settlement value is recorded, afterwards the loading is increased up to $400 \mathrm{kPa}$. During the test, the settlements are recorded after $15 \mathrm{~s}, 30 \mathrm{~s}, 1 \mathrm{~min}, 2$ $\min , 5 \mathrm{~min}, 10 \mathrm{~min}$ and $24 \mathrm{~h}$ [10], the collapse potential $\left(\mathrm{C}_{P}\right)$ is defined as:

$$
C_{p}(\%)=\left[\frac{\Delta e}{1+e_{0}}\right] \times 100
$$

$$
\begin{aligned}
& \Delta e=e_{1}-e_{2}, \\
& e_{1}: \text { void ratio before flooding } \\
& e_{2}: \text { void ratio after flooding } \\
& e_{0}: \text { initial void ratio. }
\end{aligned}
$$




\section{Results and Discussion}

\subsection{Test results without treatment}

To verify the collapse of the laboratory reconstituted soil, oedometer consolidation tests were executed at different moisture content and compaction energy. The results showed that the coefficient of collapse $C_{p}$ varies according to compaction from 11.95 to 7.3 for an initial water content of $2 \%$, from 8.74 to 6.59 for an initial water content of $4 \%$ and from 7.47 to 5.26 for an initial water content of $6 \%$. These values show a clear tendency of the untreated soil to collapse, they correspond to the variation of the state of the soil from severe to a moderate disorders according to the classification of Jennings and Knight [10] given in Table 2.

In these tests, which were carried to verify the collapsibility of the laboratory reconstituted soil, we noted that the ratio of the instant collapse is about $80 \%$ and the remaining one occurs slowly. The sudden collapse is due probably to the elimination of the capillary tension by the addition of water, the other part (slow collapse) is caused by the impermeability of the clay bridges making links between the soil grains. This confirms the mechanisms of collapse postulated by Morgenstern and de Matos[11], Ganeshan [12], Knight [13] and Booth [14].

The influence of the variation of initial water content, for different compaction energy, is clearly visible in Figure 2.The same observation can be noted for the compaction energy. Indeed, we notice that the value of $C_{p}$ decreased with increasing energy of compaction (Figure 3). This result confirms the work of Barden et al.[15], Lefebvre and Belfadhel [16] and Lawton et al.[17].

Consequently, we can notice that the laboratory prepared soils have an analogous behavior to those met in situ.

\subsection{Test results after treatment}

The results illustrated by Figures. 4, 5 and 6, represent the variation of the collapse potential $\left(C_{p}\right)$ against the treatment of the soil with different percentage of glass-fiber at different moister content.

We notice for the addition of 3\% of glass-fiber a little decrease of the collapse, $\mathrm{C}_{p}$ decreases of $14.7 \%$ for $2 \%$ of water content and a compaction energy of 20 blows, until reaching $48.12 \%$ for the same previous water contents and a compaction energy of 60 blows. For the addition of $6 \%$ of glass-fiber, $\mathrm{C}_{p}$ decreases of $55.2 \%$ for $2 \%$ of water 


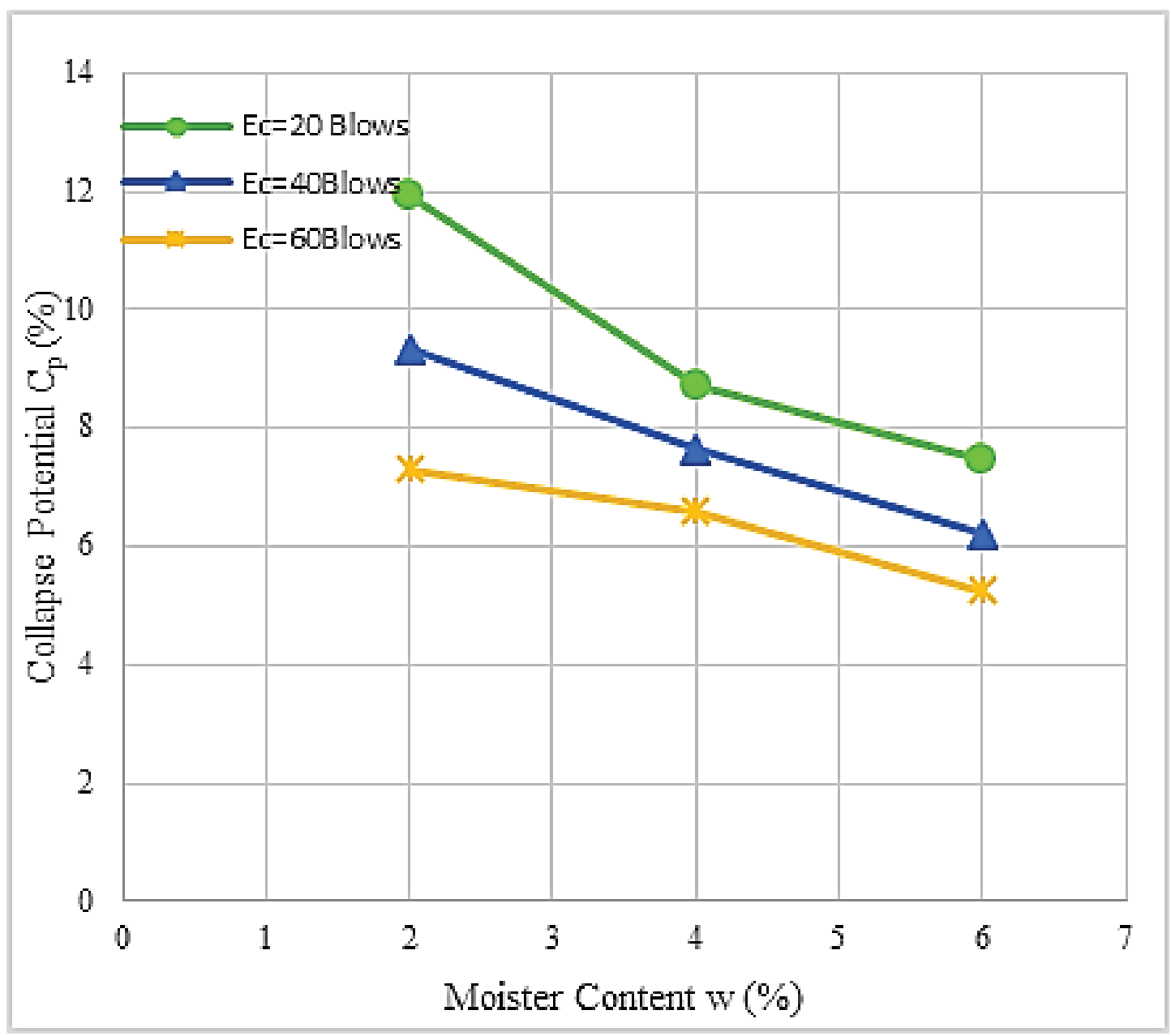

Figure 2: Variation of the collapse potential against moister content

content and a compaction energy of 20 blows, until $70.88 \%$ for the same previous water contents and a compaction energy of 60 blows (Figure 4). That is to say, that soil state passes from severe to moderate disorders according to the classification of Jennings and Knight [10], given in Table3.

When the water content is $4 \%$ (Figure 5), the results of treatment by $3 \%$ and $4 \%$ of glass-fiber (energy of compaction of 20 blows) seem to be close. The results go then from a decrease of $7.67 \%$ of $\mathrm{Cp}$, for $3 \%$ of glass-fiber $(\mathrm{Fg})$ and 20 blows, until reaching $8.12 \%$ for $4 \%$ of $\mathrm{Fg}$ and 20 blows as compaction energy.

The same remark can be done for the treatment with $5 \%$ and $6 \%$ of glass fiber for 40 blows of compaction energy.

For $6 \%$ of water content (Figure 6), the collapse becomes insignificant until it vanishes from treatment with $5 \%$ of glass fiber especially for 60 blows of compaction energy. The $\mathrm{C}_{p}$ value is $1.62 \%$ for $6 \%$ of glass fiber and 60 blows. 


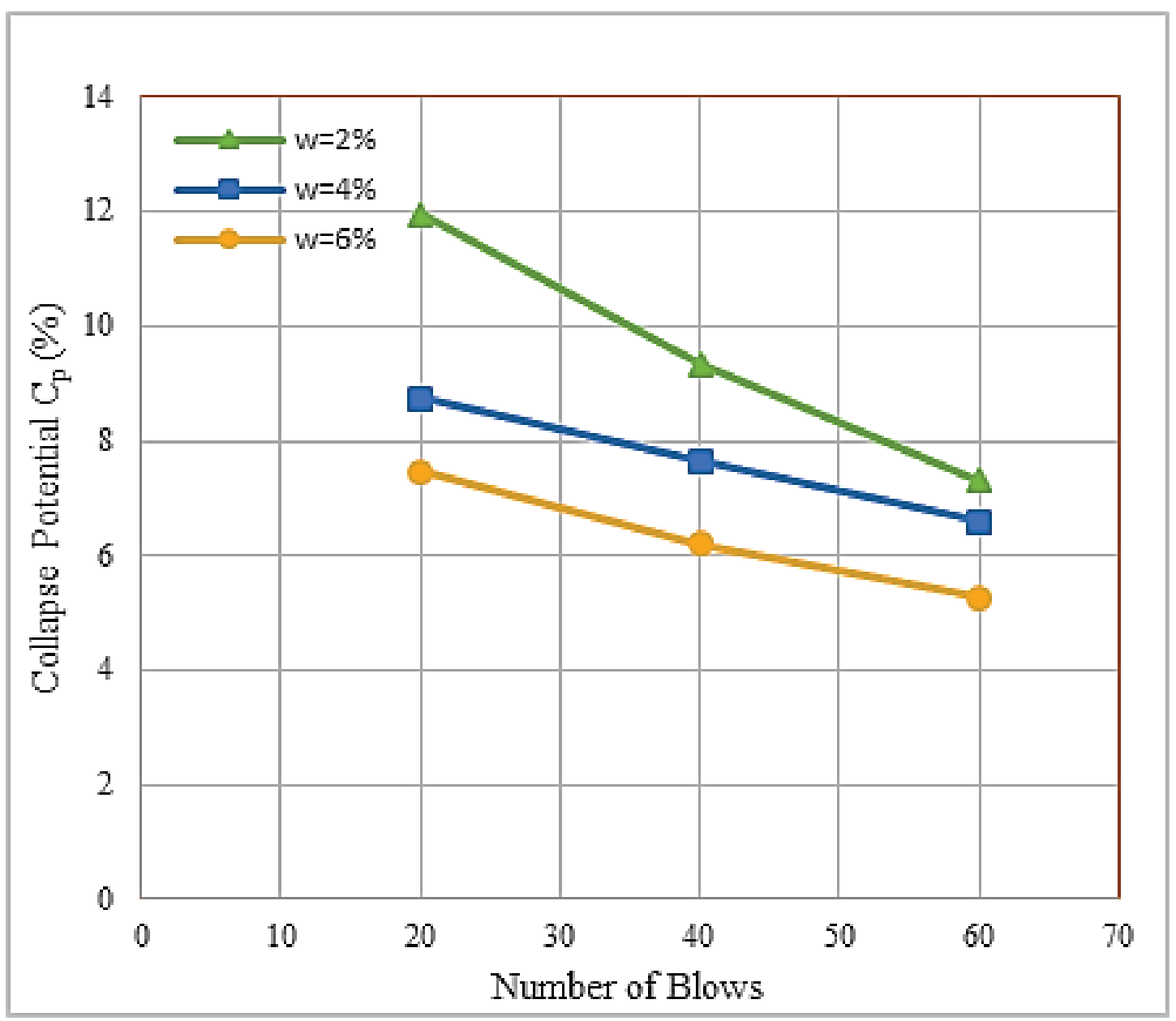

Figure 3: Variation of the collapse potential against number of blows

According to the obtained results, we can notice clearly the influence of the treatment of the soil by glass-fiber and its efficiency in reducing, or eliminating the danger of collapse of the soil and therefore structures built on it.

\section{Conclusion}

In this work, soil samples were prepared at the laboratory, and then they were treated with different percentages of glass-fiber in order to improve their mechanical characteristics and to eliminate the collapse problem. The results of physical and mechanical tests show that the laboratory reconstituted soil, with a water content lower than the optimum of Proctor and a moderate compaction energy, manifests the same physical and mechanical characteristics of a natural collapsible soil. The mechanical tests show clearly the variation of the collapse according to the augmentation of water content percentage and compaction energy. The oedometer results confirm the efficiency of the treatment with the glass fiber, and show that we can get a soil with moderate disorders 


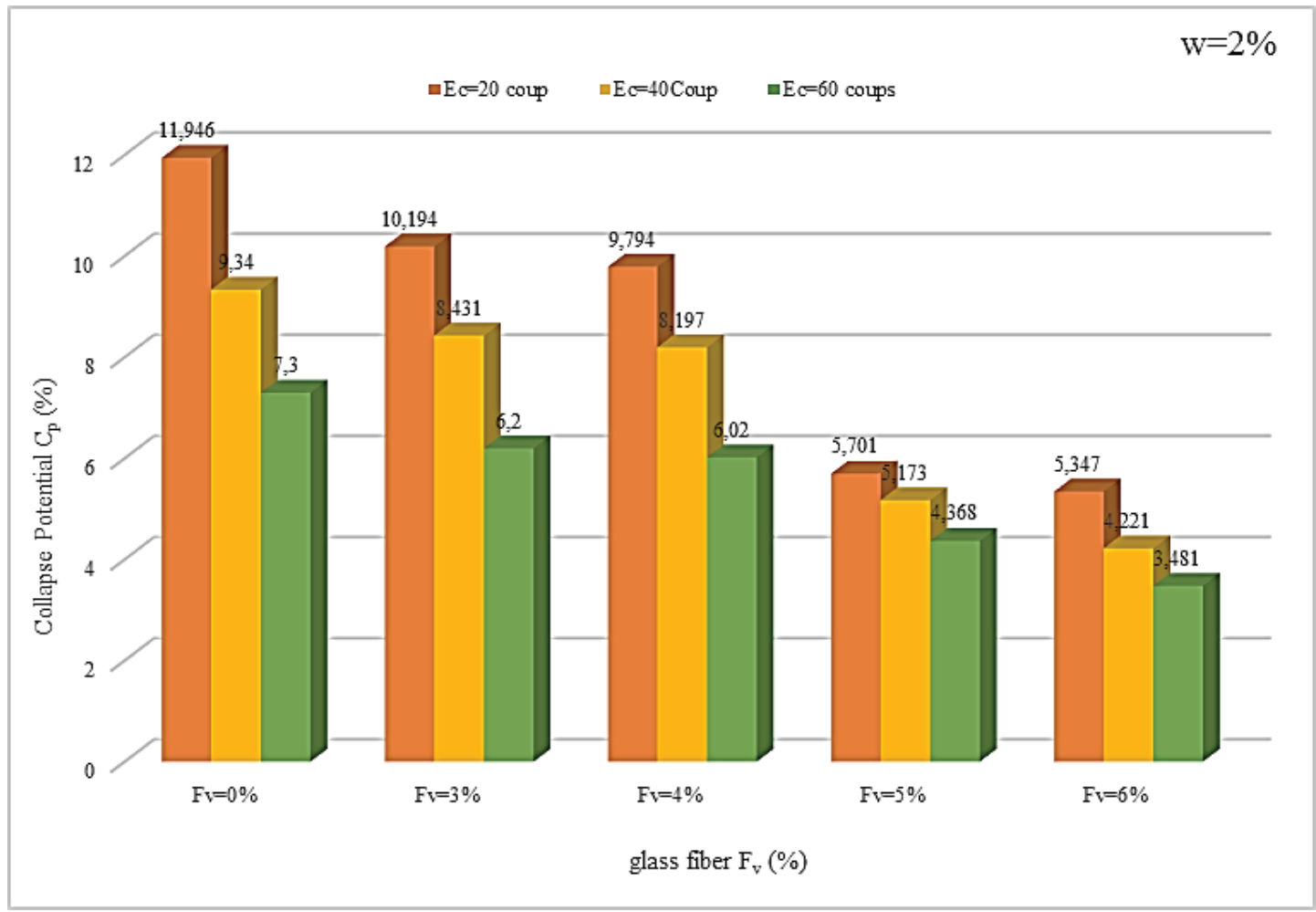

Figure 4: The Collapse Potential of soils compacted at various number of blow against glass fiber contents, $\mathrm{w}=2 \%$

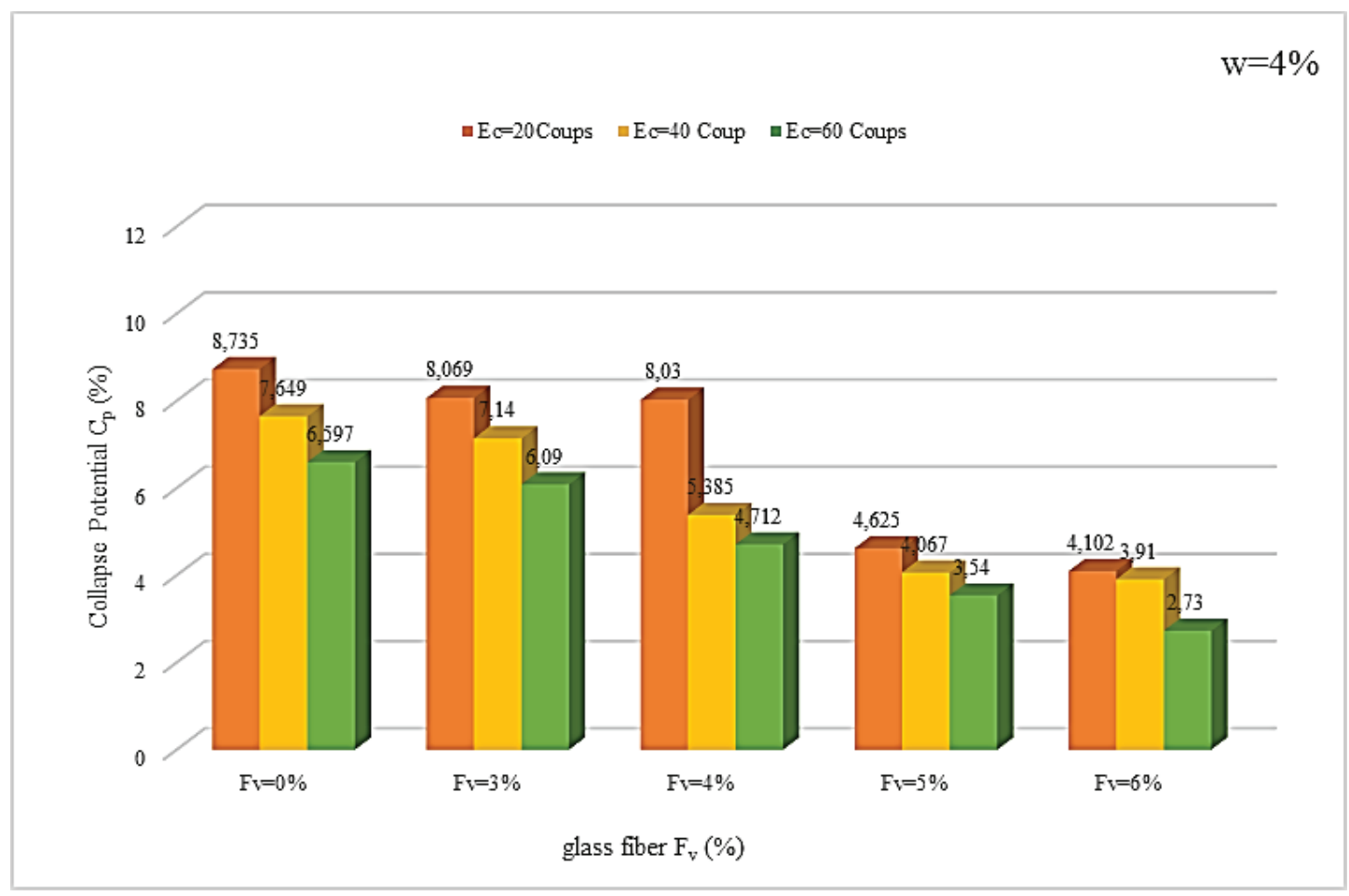

Figure 5: The Collapse Potential of soils compacted at various number of blow against glass fiber contents $(w=4 \%)$ 


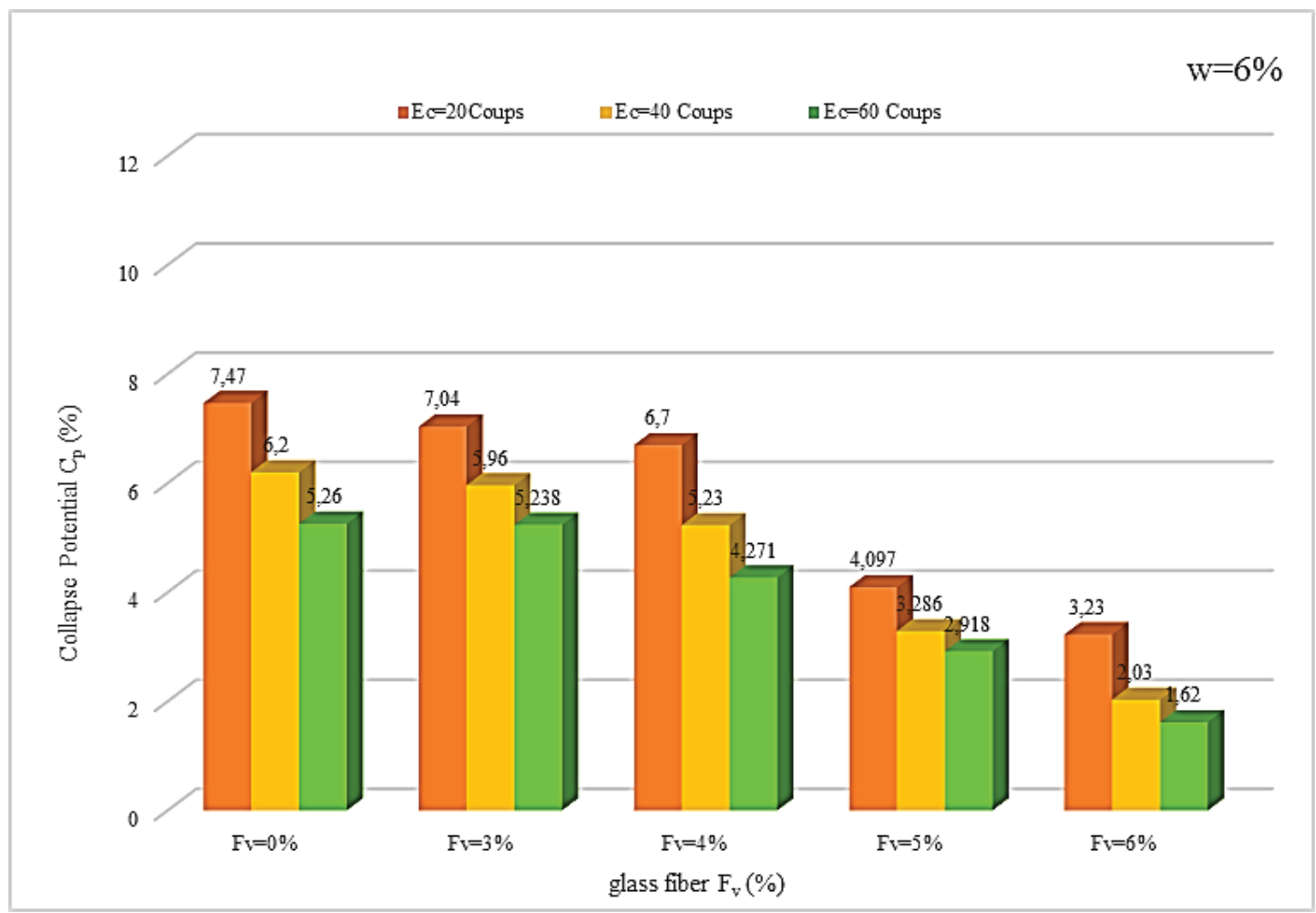

Figure 6: The Collapse Potential of soils compacted at various number of blow against glass fiber contents, $\mathrm{w}=6 \%$

since adding $5 \%$ of glass fiber at different cases of water content and compaction energy.

Finally, it can be concluded that for the evolution of the reduction of collapse with the addition of milled glass fiber, soil without disorder can be obtained for a treatment upper to $6 \%$ of fiber content.

\section{References}

[1] Clemence, S.P. and Finbarr, A.O. (1981). Design considerations for collapsible soils. Journal of Geotechnical Engineering. Div, ASCE, vol. 107, pp. 305-317.

[2] Nouaouria, M.S., Guenfoud, M. and Lafifi, B.(2008). Engineering properties of loess in Algeria. Engineering Geology, vol. 99, issue (1-2), pp. 85-90.

[3] Abbeche, K., Ayadat, T. and Lahmadi Z. (2009). Traitement d'un sol à effondrement brusque par la chaux. Séminaire International, Innovation et Valorisation dans le Génie Civil (INVACO1). Hammamet, Tunisie,pp. 161-168.

[4] Lahmadi, A., Abbeche, K. and Bakir, N. (2012). Traitement d'un sol à éffondrement brusque par le ciment en utilisant la méthode double consolidation. 2ème Colloque International sur les Sols non Saturés et Environnement (UNSAT). Alger, Algerie, 
Novembre.

[5] Mohamed, A.M. and El Gamal, M. (2012). Treatment of collapsible soils using sulfur cement. International Journal of Geotechnical Engineering, 6(1), 65-77.

[6] Fattah, M.Y., Al-Ani, M.M. and Al-Lamy, M.T.A. (2013). Treatment of Collapse of Gypseous Soils by Grouting, Proceedings of the Institution of Civil Engineers, Ground Improvement, UK, February.

[7] Fattah, M.Y., Al-Ani, M.M. and Al-Lamy, M.T.A. (2014). Studying Collapse Potential of Gypseous Soils Treated by Grouting, Soils and Foundations Journal, 54(3), 396-404.

[8] Fattah, M.Y., Al-Ani, M.M. and Al-Lamy, M.T.A. (2015). Wetting and Drying Collapse Behaviour of Collapsible Gypseous Soils Treated by Grouting, Arabian Journal of Geosciences, 8 (4), 2035-2049.

[9] ASTM D 5333-03 (2003), Standard test method for measurement of collapse potential of soils. ASTM International. United States.

[10] Jennings, J.K. and Knight, K. (1975). The additional settlement of foundation due to collapse of sandy subsoils on wetting. Proceeding of 4th International Conference on Soil Mechanics and Foundation Engineering.

[11] Morgenstern, N. and de Matos, M.M. (1975). Stability of Slopes in Residual Soils, Proc. 5th. Pan American Conf. on SMFE, Buenos Aires, Argentina.

[12] Ganeshan, V. (1982). Strength and Collapse Characteristics of Compacted Residual Soils, Thesis (M.E.), Asian Institute of Technology, Bangkok, Thailand.

[13] Knight, K. (1961). The Collapse of Structure of Sandy Subsoil on Wetting, Ph.D. Thesis, University of the Witwatersrand, Johannesburg, South Africa.

[14] Booth, A.R. (1975). The Factors Influencing Collapse Settlement in Compacted Soils. Proceeding of the 6th, Regional Conference for Africa on Soil Mechanics and Foundation Engineering, Dublin, South Africa. Vol. 1: 57-63

[15] Barden, L., Madedar, A.O. and Sides, G.R. (1969). Volume Change Characteristics of Unsaturated Clay, Journal of SMFE, ASCE, 95 (1), p. 33-49.

[16] Lefebvre, G. and Belfadhel, M.B. (1989). Collapse at Permeation for a Compacted Non-Plastic till, Proc.12th.ICSMFE, pp. 619-622, Rio de Janeiro.

[17] Lawton, E.C., Fragaszy, R.J. and Hardcastle, J.H. (1989). Collapse of Compacted Clayey Sand, Journal of Geotechnical Engineering ASCE, 155, 1252-1267. 